\title{
HOST SPECIALIZATION IN THE RUST OF IRIS, PUCCINIA IRIDIS ${ }^{1}$
}

E. B. MAIN S

(Received for publication January I0, 1933)

\section{INTRODUCTION}

The rust of iris, Puccinia Iridis (DC.) Wallr., is widely distributed. The Sydows (Ig04) list it from Europe, Asia, Japan, and North America. In North America, Arthur (1920) gives the distribution as nearly throughout the United States and Canada.

The rust is usually found in the uredinial stage. Arthur reports only uredinia east of the Rocky Mountains in the United States. The Sydows state that in many places it is found only in the uredinial stage, while in others telia appear simultaneously with the uredinia or following them in late fall or winter. Plowright (1889) notes that teliospores developed, in England, only on the species Iris foetidissima and I. pseudacorus. He states that the cultivated species, $I$. flavissima, I. spuria, I. ensata, I. decora (=I. nepalensis D. Don), I. Kingii, I. pumila, I. filifolia, I. caucasica, I. iberica, and I. tolmieana ( $=I$. missouriensis), developed only uredinia.

The aecial stage has only been reported by Tranzschel (1923), who obtained aecia on Valeriana officinalis by inoculations from Iris sibirica.

The Sydows list as hosts for the species Iris aequiloba (=I. pumila), I. caucasica, I. decora (=I. nepalensis), I. dichotoma, I. Douglasiana, I. ensata, I. filifolia, I. flavescens, I. flavissima, I. florentina, I. foetidissima, I. fumosa (=I. sindjarensis), I. fuscata (? probably $I$. furcata $=I$. aphylla), I. germanica, I. gracilis ( $?=I$. aphylla, or $I$. prismatica or $I$. goniocarpa), $I$. graminea, I. Hartwegi, I. iberica, I. Kingii (?), I. longipetala, I. ochroleuca, I. Pallasii, I. pallida, I. pseudacorus, I. pseudopumila, I. pumila, I. ruthenica, I. spuria, I. tectorum, I. tolmieana (=I. missouriensis), I. versicolor, I. virginica, and $I$. xiphioides. Although many of these species have been cultivated in the United States, Arthur reports the rust as occurring only on Iris Douglasiana Herb., I. fulva Ker., I. longipetala Herb., I. missouriensis Nutt., I. tuberosa L. (= Hermodactylus tuberosus Mill.), $I$. versicolor L., and $I$. Xiphium L.

Plowright ( 1889 ) has shown that the rust of iris in England could be separated into two groups according to host specialization. He found that

1 This investigation was started while the writer was a member of the Department of Botany, Agricultural Experiment Station, Purdue University, and has been continued at the University of Michigan. Paper from the Department of Botany of the University of Michigan and the University Herbarium No. 398. 
the rust from such species as "Iris iberica, I. tolmieana, etc." produced no effect on 1 . foetidissima and I. pseudacorus. He also states that Dr. M. Foster noted that the rust in his collection of Iris which attacked I. flavissima, I. tolmieana, I. iberica, I. spuria, I. ensata, I. decora, I. Kingii, I. pumila, $I$. filifolia, $I$. caucasica, and species from Central Asia did not readily infect the broad-leaved Mediterranean forms such as "I. germanica, I. pallida, etc." Also, since the rust of $I$. foetidissima and $I$. pseudacorus produced telia while

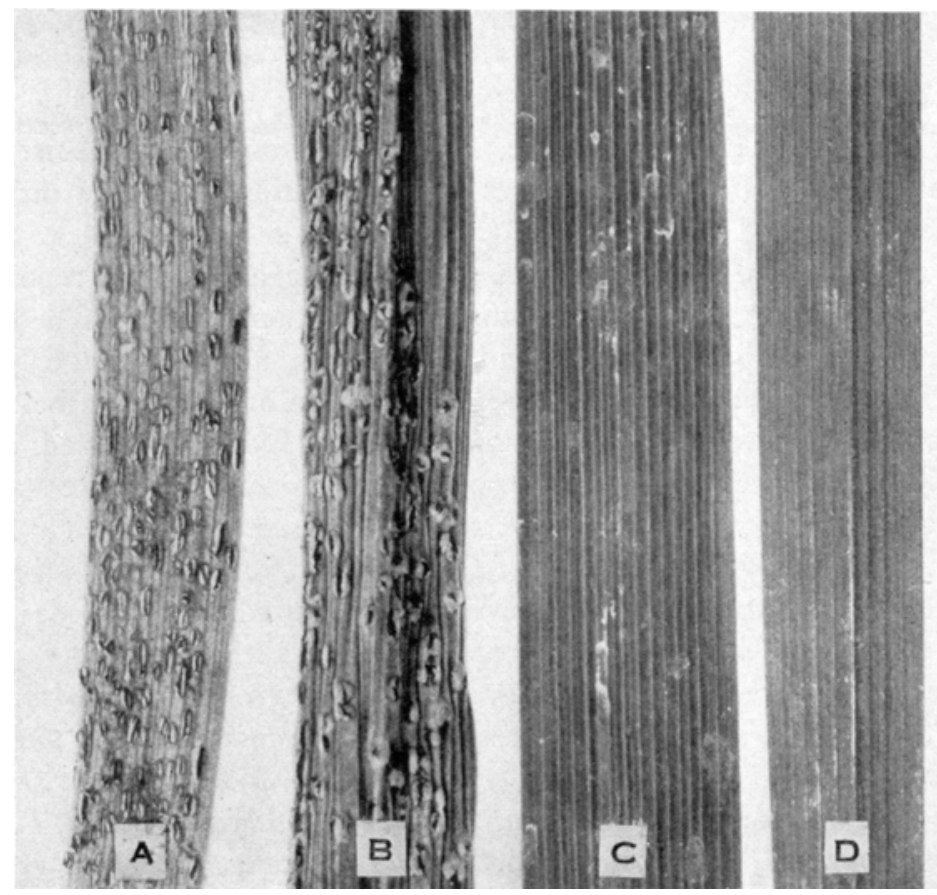

Fig. I. Reaction to Puccinia Iridis sp. f. australis. A. Iris missouriensis (175), susceptible. B. I. xiphioides (Prince of Wales), susceptible. C. I. Douglasiana, highly resistant. D. I. graminea (X 9I), highly resistant. (Reduced.)

that of the cultivated species did not, Plowright apparently concluded that he was dealing with two rusts, Puccinia Iridis and Uredo Iridis.

In I927, Professor H. S. Jackson called the writer's attention to rust on Iris fulva in his garden. Since the writer was personally interested in iris and had a small collection of species in his garden, it seemed a good opportunity to study the question of host specialization. Later collections of rust on the variety Dorothea $\mathrm{K}$. Williamson at Remington, Indiana, on $I$. virginica at Coldwater, Michigan, and on I. spuria at Ann Arbor, Michigan, made pos-, sible a comparison of the host specialization of the rust from different sources. During this investigation 33 species were studied. These may be arranged 
according to the treatment in Dykes Monograph of the Genus Iris (I9I3) as follows :

Apogon Section: Iris sibirica L., I. orientalis Thunb., I. Clarkei Baker, I. Bulleyana Dykes, I. Douglasiana Herbert, I. tenax Douglas, I. Purdyii Eastwood, I. foetidissima L., I. unguicularis Poir. (stylosa), I. spuria L. (I. halophila Pallas, I. ochroleuca. L., I. aurea Lindley), I. graminea L., I. sintenisii Janka, I. Kaempferi Siebold ex Lemaire, I. pseudacorus L., I. versicolor L. (I. virginica L.) ${ }^{2}$ I. hexagona Walt., I. foliosa Mackenzie \& Bush, I. fulva

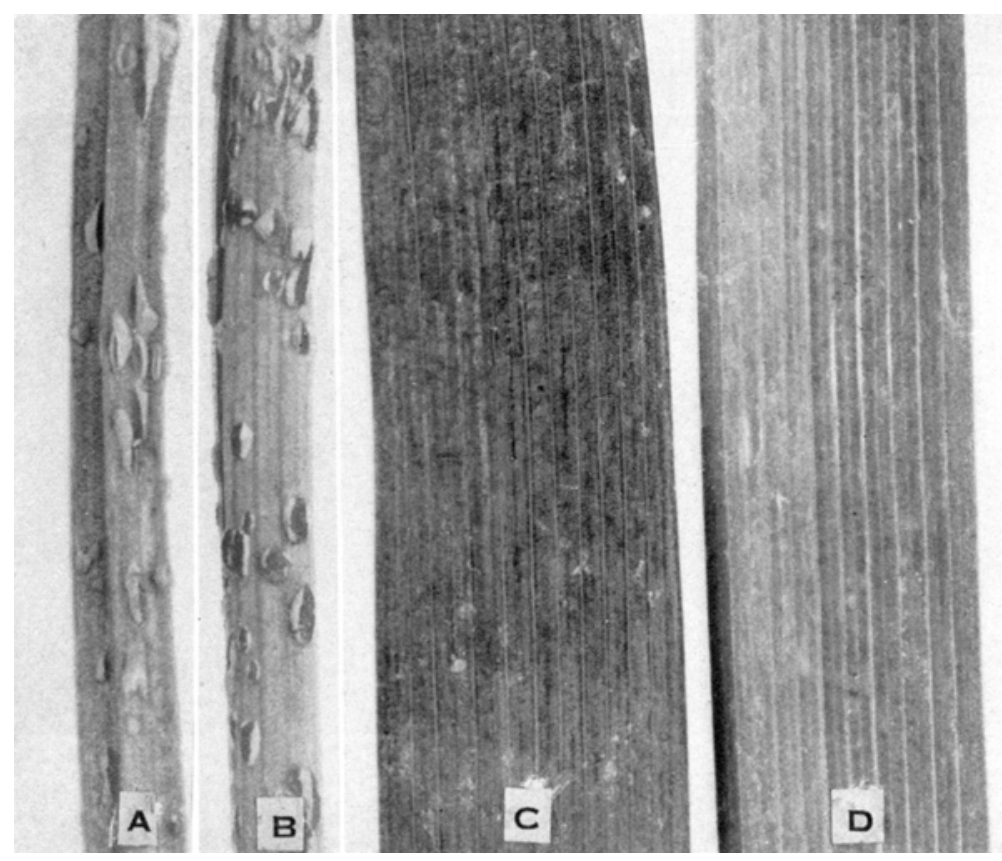

Fig. 2. Reaction to Puccinia Iridis sp. f. australis. A. Hermodactylus tuberosus, very susceptible. B. Iris Xiphium, very susceptible. C. Iris foetidissima (r 49), highly resistant. D. Iris spuria (ochroleuca ${ }_{158}$ ), highly resistant. (About natural size.)

Ker-Gawl., I. ensata Thunb., I. missouriensis Nutt., I. setosa Pallas, I. verna L.

Pardanthopsis section: Iris dichotoma Pallas.

Evansia section: Iris tectorum Maxim., I. cristata Solander (I. lacustris Nutt.).

Oncocyclus section: Iris susiana L. Also a hybrid with an iris of the Regelia section under the name of $I$. regelio-cyclus.

Pogoniris section: Iris pumila L., I. variegata L., I. Kochii A. Kerner, I. mesopotamica Dykes. There is considerable confusion in regard to the spe-

2 A study by E. Anderson (Ann. Missouri Bot. Garden 15: 24I-332. I928) indicates that this is probably a distinct species. 
cies in this section. Among the varieties of bearded iris studied, such types as I. florentina Lam., I. germanica L., I. pallida Lam., I. favescens DC., and I. trojana Kerner were represented.

Xiphium section: Iris xiphioides Ehrh., I. Xiphium L., and I. filifolia Boiss.

In a. number of species, plants were obtained from several different sources. For this reason, in giving the results, the species is usually fol-

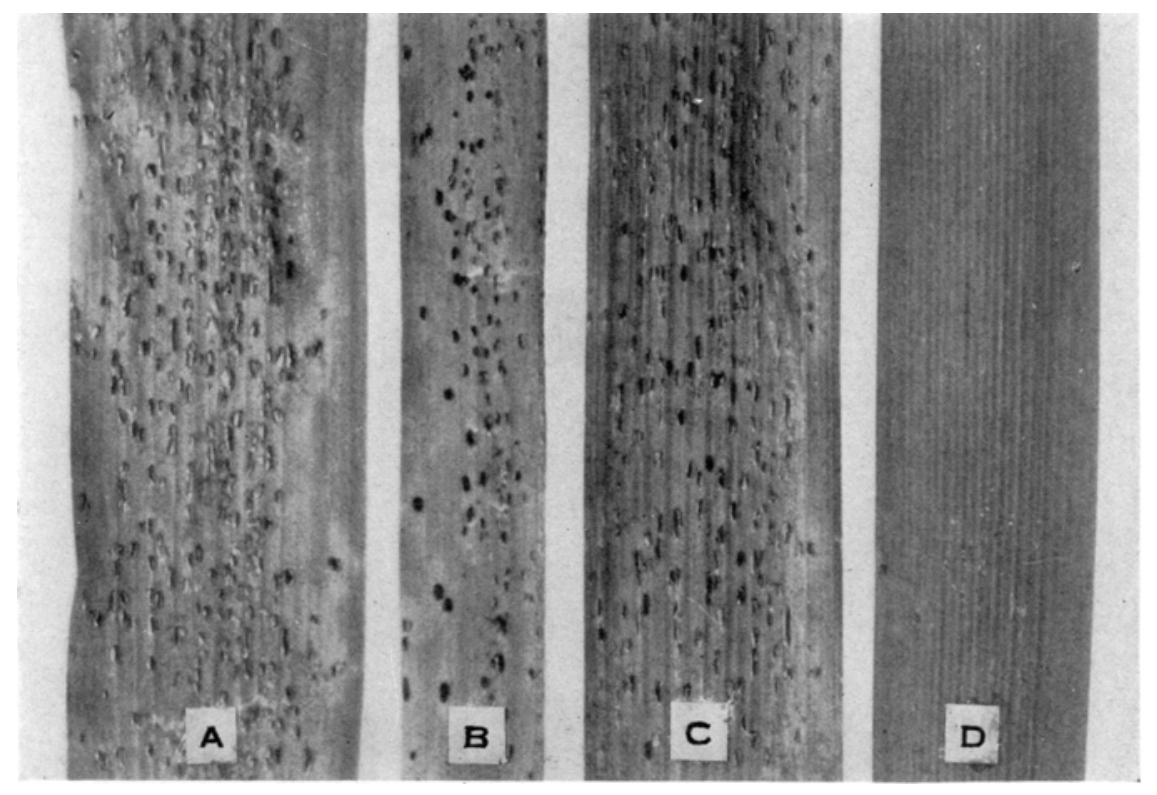

Fig. 3. Reaction to Puccinia Iridis sp. f. septentrinalis. A. Iris foliosa (165), susceptible. B. Iris fulva (32), susceptible. C. Dorothea K. Williamson (G 3) (I. fulva $\times$. I. foliosa), susceptible. D. Dorothea K. Williamson (I Io) (I. fulva $\times$ I. foliosa), highly resistant. (Reduced.)

lowed by the accession number or in some cases varietal name of the particular strain employed. The varieties of the bearded iris are mostly listed under their horticultural names.

For the most part the inoculations were made in the greenhouse under temperatures and conditions of humidity favorable for spore germination and infection. In the garden, notes were taken only after repeated exposures to infection by dusting with spores and exposure to natural inoculation from rusted species.

\section{RESULTS WITH CULTURE I I}

This culture of rust was obtained from rusted Iris fulva at Lafayette, Indiana, and was studied in the greenhouse during November, February, and April. The following proved to be very susceptible: Iris foliosa (165), 


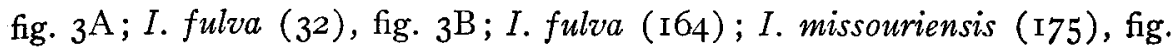
IA; I. regelio-cyclus; I. spuria ( 128 ); I. spuria (desertorum X $\mathrm{I} 43$ ); I. susiana; I. virginica $(\mathrm{C} 2)$; I. xiphioides (varieties Prince of Wales, fig. IB, and Royal Blue); I. Xiphium, fig. 2B (varieties Cajanus and Reconnaisance); and Hermodactylus tuberosus (I. tuberosa), fig. $2 \mathrm{~A}$. Iris dichotoma (100) gave a somewhat variable reaction. One inoculation resulted in a moderate production of well-developed uredinia and was classed as moderately susceptible. Another resulted in the development of considerable chlorosis and necrosis surrounding the uredinia and was classed as moderately resistant. Iris filifolia (variety Hort Nibbrig), I. spuria (ochroleuca X 75), and I. virginica $\left(\mathrm{C}_{3}\right)$ were moderately resistant. I. Douglasiana, fig. IC, I. foetidissima ( 149 ), fig. 2C, I. graminea (X 9I), fig. ID, I. pseudacorus (33), I. sibirica (X 94), I. spuria (aurea I 57), I. spuria (ochroleuca I 58), fig. $2 \mathrm{D}, I$. tectorum (X 76), I. tenax, I. verna ( I69), and I. virginica (C. L.) were extremely resistant, showing only slight flecks or exhibiting no signs of infection. The varieties Carthusian, Fairy, $\mathrm{Ma}$ Mie, and Pallida Dalmatica, horticultural varieties of bearded iris, were also extremely resistant.

A study of the variety Dorothea $\mathrm{K}$. Williamson proved to be very interesting. Plants from the stock ( I IO) were very resistant to I I, fig. $3 \mathrm{D}$. Plants of the same variety obtained from a planting at Remington, Indiana, showed marked differences in reaction. Plants $\mathrm{G}_{2}$ and $\mathrm{G}_{3}$, fig. ${ }_{3} \mathrm{C}$, were very susceptible, while $G_{I}$ was highly resistant, showing only a slight necrosis. As a result of an inquiry concerning the history of the variety, Mr. E. B. Williamson stated that it was obtained by pollinating Iris fulva by I. foliosa. About 300 plants were raised from the seed thus produced. These showed considerable variation in color from very red through various gradations to intense purple. Mr. Williamson believed that he discarded all except one of the most intense purples which he named Dorothea $\mathrm{K}$. Williamson. The discards were given to a number of people. Supposedly the variety has been vegetatively propagated from one plant and should, therefore, be uniform in its rust reaction. It is possible that the differences noted may have developed through bud sports. Mr. Williamson had suggested that some of those receiving discarded seedlings may have noted the close similarity of some of the intense purples to Dorothea $\mathrm{K}$. Williamson and may have propagated such under that name. The variety also seeds fairly abundantly, and some of the seedlings may have become mixed with the variety.

Culture I I of the rust was used to inoculate a number of species and varieties in the writer's garden during the summer of 1928. Iris Clarkei (X I66), I. foliosa ( 165 ), I fulva (32 and I64), I. missouriensis (tolmieana I 50), I. setosa (X 69), I. Sintenisii ( 162), I. spuria (halophila 99), and $I$. spuria (I23) were very susceptible. Iris Bulleyana (X 8I), I. foliosa ( I 55), I. setosa (X 47), I. spuria (halophila X 89), I. spuria (X 44, I63, I28, I2 I, and $\mathrm{I} 22$ ), and $I$. virginica (X 92, I30) were moderately resistant. Iris cristata (55), I. cristata (lacustris I25), I. dichotoma ( 100$)$, I. ensata (X 78, 98. 
X 83), I. graminea (126, I67), I. hexagona (156), I. Kaempferi, I. Kochii ( 137 ), I. mesopotamica (II5), I. orientalis (X 167, X I88, 42), I. pseudacorus (129, X 93, X.70, 33), I. pumila $(3 \mathrm{I}, 56)$, I. sibirica (X 94, X 82, 95, 30), I. spuria (aurea I57), I. spuria (halophila 127), I. spuria (ochroleuca 166, I58, I18), I. tectorum (X 76), I. unguicularis (stylosa III), I. variegata (X 80), and $I$. verna ( I69) were highly resistant. The beardless variety Dorothea K. Williamson (IIO) showed only brownish spots.

The following bearded iris varieties were highly resistant, showing no signs of infection although repeatedly inoculated: Afterglow, Albert Victor, Alcazar, Anna Farr, Aurea, Ballerine, Blue Boy, Blue Jay, Caprice, Carthusian, Celeste, Dalila, Dr. Bernice, Fairy, Flavescens, Florentina, Georgia, Gertrude, Gypsy Queen, Her Majesty, Honorabile, Iris King, Isoline, James Boyd, Jacquesiana, Juniata, Lent A. Williamson, Lohengrin, Loreley, Mary Garden, May Queen, Mme. Chereau, Mithras, Monsignor, Mrs. H. Darwin, Mrs. Neubronner, Nine Wells, Oriflamme, Othello, Pallida Dalmatica, Pare de Neuilly, Parisiana, Perfection, Powhatan, Purple King, Quaker Lady, Queen Alexandria, Queen Caterina, Rhein Nixe, Sarpedon, Sherwin Wright, Storm Cloud, Violacea Grandiflora, Virginia Moore, and White Knight.

In only one instance did teliospores develop. These occurred abundantly on Iris Clarkei in the autumn. Tranzschel (1923) has reported connecting the rust of Iris with aecia on Valeriana. He very kindly furnished seed of several species of Valeriana, and plants were placed beside the over-wintered telia in the spring of 1930. However, no infection resulted. It is doubtful whether these negative results are of any significance, since tests of the teliospores did not show germination.

\section{RESULTS WITH CULTURE I 2}

In July, I928, a collection of rust on the variety Dorothea $\mathrm{K}$. Williamson obtained at Remington, Indiana, was received from Mr. H. F. Dietz. This collection ( $\mathrm{I}$ 2) was especially interesting, since Dorothea $\mathrm{K}$. Williamson (I IO) had previously been very resistant to culture I I. The rust was propagated on the rusted plants obtained from Remington, Indiana, and was studied in the greenhouse during the winter of $1928-1929$.

The species Iris missouriensis (I75), I. spuria (desertorum $\mathrm{X}$ I43), $I$. xiphioides (variety Royal Blue), and Hermodactylus tuberosus were very susceptible. Iris fulva (32), fig. $4 \mathrm{~B}$, was very resistant, showing only slight necrosis or occasionally a few small uredinia. Iris pseudacorus (33), I. spuria (aurea $\mathrm{I} 57$ ), I. tectorum (X 76 ), and $I$. virginica (C. L.) were highly resistant, showing no signs of infection.

The variety Dorothea $\mathrm{K}$. Williamson showed similar reactions as given under I I. The strains IIO and G I were very resistant, while the strains $\mathrm{G} 2$ and $\mathrm{G} 3$ were susceptible.

Culture I 2 showed one important difference from I I. Iris fulva (32), which was very susceptible to $I I$, was very resistant to $I 2$, showing considerable necrosis and developing only a few small uredinia, fig. 4 . 

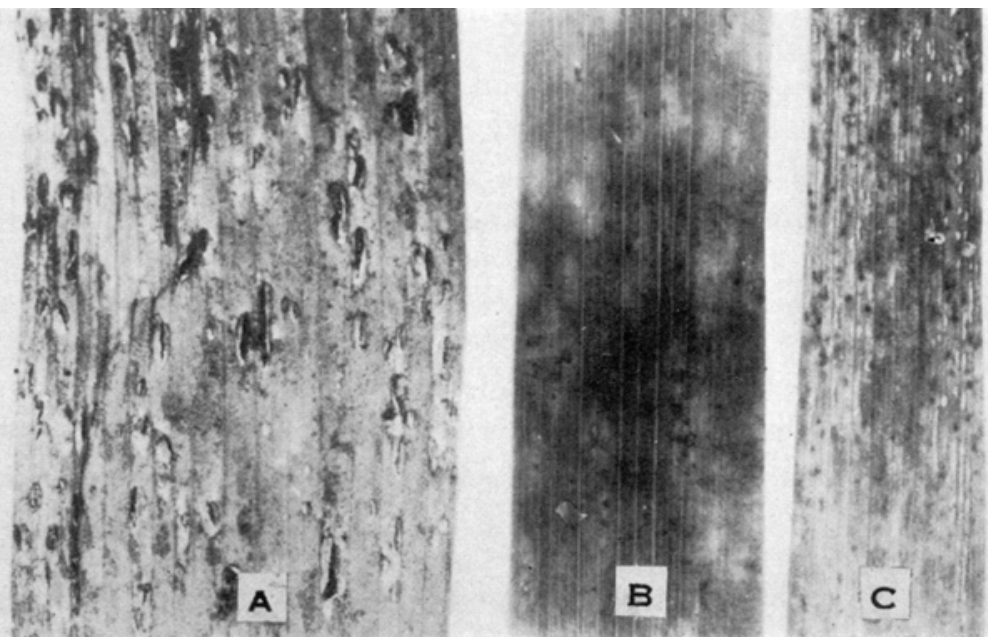

Fig. 4. Reaction of Iris fulva to races of Puccinia Iridis. A. To race australis, very susceptible, culture I I from I. fulva, West Lafayette, Indiana. B and C. To race septentrinalis. B. Culture I 2 from Dorothea K. Williamson, Remington, Indiana. C. Culture I 3 from Iris virginica, Coldwater, Michigan. (Somewhat enlarged.)

\section{RESULTS WITH CULTURE I 3}

During the summer of 1928, the writer collected rust on plants of Iris virginica at Coldwater, Michigan. At the time of collection, it was noted that several plants were heavily rusted, while adjacent plants were free. Both rusted and rust-free plants were collected and grown in the greenhouse. The rust was propagated on the rusted plants and studied during the winter of I928-1929.

The species Iris dichotoma ( 100$)$, I. regelio-cyclus, I. xiphioides (varieties Prince of Wales and Royal Blue), $I$. Xiphium (variety Cajanus), and Hermodactylus tuberosus were very susceptible.

Iris virginica showed very interesting differences. The rusted plants ( $\mathrm{C}$ I and $\mathrm{C}_{2}$ ) upon which the rust was collected continued to be very susceptible. Of the adjacent rust-free plants, one ( $\mathrm{C}_{3}$ ) was moderately susceptible, developing fewer and smaller uredinia than $\mathrm{C}_{\mathrm{I}}$ and $\mathrm{C} 2$. Two plants ( $\mathrm{C}_{4}$ and $\mathrm{C}$ 5) were very resistant, developing only a few small uredinia accompanied by necrosis. Two other collections (CR and CL) of Iris virginica were also very resistant.

The various strains of Dorothea $\mathrm{K}$. Williamson gave similar reactions to those given to cultures $I$ I and I 2 , strain $G 2$ being very susceptible, while strains I IO and G I were very resistant.

Iris fulva (32), fig. $4 \mathrm{C}$, showed considerable resistance, developing a moderate number of small uredinia accompanied by necrosis. Iris fulva (I64) was more resistant, only a few very small uredinia accompanied by necrosis being produced. 
Iris Douglasiana, I. foetidissima (141), I. foliosa (165), I. pseudacorus (33), I. sibirica (X 94), I. spuria (ochroleuca $\mathrm{I} 58$ ), and I. tectorum (X 76 ) were highly resistant, only occasionally showing slight flecking. The varieties, Carthusian, Fairy, Ma Mie, and Pallida Dalmatica of the bearded iris, showed no signs of infection.

During the summer of 1929 this culture was used to inoculate a series of species and varieties of iris in the writer's garden, since the rust from culture I I used the previous summer had not survived. Iris missouriensis ( I 50), I. setosa (X 69), I. spuria (halophila 99), and I. xiphioides (Royal Blue) were severely rusted. Of a number of seedlings of Iris spuria (X 77), one was very susceptible, while a number were resistant, showing only a trace of rust. Iris Bulleyana (X 9I), I. cristata (lacustris I25), I. dichotoma ( 100$)$, I. setosa (X 47 ), and $I$. virginica (X 92) were moderately resistant. Iris ensata ( $98, \mathrm{X} 78, \mathrm{X} 83$ ), I. fulva (32), I. graminea ( 126), I. Kaempferi, I. orientalis ( $142, \mathrm{X} \mathrm{I} 88$ ), I. pseudacorus (X 93, X 70, 33), I. sibirica (30, $95, \mathrm{X} 82$ ), I. tectorum (X 76), I. unguicularis (stylosa III), and 1 . virginica (54) were highly resistant, either showing no signs of infection or only slight brown flecks.

The beardless variety, Dorothea K. Williamson ( 1 Io), showed only slight brown flecks. The following varieties of bearded iris showed no signs of infection: Albert Victor, Aurea, Ballerine, Blue Boy, Blue Jay, Caprice, Carthusian, Celeste, Dr. Bernice, Fairy, Flavescens, Florentina, Georgia, Gypsy Queen, Her Majesty, Honorabile, Iris King, James Boyd, Jacquesiana, Lent A. Williamson, Lohengrin, Loreley, Mary Garden, May Queen, Mme. Chereau, Mithras, Monsignor, Mrs. H. Darwin, Mrs. Neubronner, Nine Wells, Pallida Dalmatica, Parisiana, Parc de Neuilly, Perfection, Purple King, Quaker Lady, Queen Alexandria, Queen Caterina, Rhine Nixe, Sherwin Wright, Storm Cloud, Violacea Grandiflora, and White Knight.

\section{RESULTS WITH CULTURE I 4}

This culture was obtained from Iris spuria in the Botanical Garden of the University of Michigan, Ann Arbor, Michigan, in the summer of 1931 . Rusted plants were transplanted to the greenhouse of the Botanical Garden in the autumn and the rust was studied during the winter of 1931-1932. Iris dichotoma (BG 4862), I. spuria (BG $\mathrm{r} 2685$, BG 9I66, BG 6752), I. versicolor (BG I32I9), and $I$. Xiphium were susceptible.

Iris spuria (BG 7097) was moderately resistant. Iris fulva ( 32 and ${ }_{164}$ ) was resistant, showing only small uredinia accompanied by necrosis. Iris Douglasiana ( 1560 ), I. ensata (BG 10697), I. graminea (X 9I and BG 7069), I. mesopotamica (I I5), I. pumila (BG 553I), I. Purdyii (I558), I. sibirica (BG 6703), I. spuria (BG 12683), I. tenax ( 1559), I. verna ( I69), and the variety Dorothea $\mathrm{K}$. Williamson ( I Io) were highly resistant. The group here listed under $I$. spuria contains a number of intergrading forms, many of which have been recognized as species by some botanists. It is 
evident that the group also shows considerable variation in its rust reaction. Iris tectorum (X 76 ) produced a few well-developed uredinia as the result of one inoculation. In other tests only somewhat indistinct chlorotic spots were developed. The bearded iris varieties, Afterglow, Alcazar, Fairy, George Tribolet, Mrs. Neubronner, and Sherwin Wright, showed no evidence of infection following inoculation.

This culture agrees very well with cultures I 2 and I 3 , especially in the resistance of Iris fulva, and differs in this respect from culture I I to which that species was susceptible.

\section{SUMMARY AND CONCLUSIONS}

From results which have been given it is evident that there are at least two races of Puccinia Iridis. These may be designated as follows:

\section{Puccinia Iridis sp. f. australis}

This race is distinguished by the marked susceptibility of Iris fulva ( 32 and 164), fig. 4A, and Iris foliosa (165). It was obtained from Iris fulva. at West Lafayette, Indiana.

\section{Puccinia Iridis sp. f. septentrionalis}

This race is distinguished by the marked resistance of Iris fulva ( $3^{2}$ and I64), fig. $4 \mathrm{~B}, \mathrm{C}$, and Iris foliosa ( 165 ). It was collected on Iris virginica at Coldwater, Michigan, on Iris spuria at Ann Arbor, Michigan, and on the variety Dorothea K. Williamson ( . fulva $\times I$. foliosa) at Remington, Indiana.

Other than the differences exhibited by the reactions of Iris fulva and I. foliosa, the two races produced very similar reactions on the species and varieties investigated. According to the classification of Dykes (I9I3), species were studied in the sections Apogon, Pardanthopsis, Evansia, Pogoniris, and Xiphium. The collections of rust were all obtained from species in the section Apogon.

In the sibirica group of the Apogon section, Iris sibirica and I. orientalis were highly resistant. I. Bulleyana showed moderate resistance and I. Clarkei was very susceptible. Abundant telia developed on the last species.

In the spuria group of the Apogon section, Iris graminea was highly resistant. Iris spuria showed considerable variation in reaction. Very susceptible, moderately resistant, and highly resistant strains were found. This species is apparently very variable and contains a number of forms which have been considered distinct species by some authors. There is considerable intergradation and many of the forms and subspecies cannot be separated with certainty. As far as studied, the subspecies aurea and ochrolenca were more or less resistant. The variety halophila was found to contain both resistant and susceptible individuals. The Sydows (I904) list both Iris graminea and $I$. ochroleuca as hosts for the rust. 
In the California group of the Apogon section the three species studied, Iris Douglasiana, I. tenax, and I. Purdyii, were all highly resistant. The Sydows (1904) give I. Douglasiana and Arthur (1920) I. Douglasiana and I. tenax as favorable hosts for the rust.

In the scarlet-seeded group of the Apogon section, the only species, Iris foetidissima, was highly resistant. The Sydows (1904) list this as a host for the rust.

In the unguicularis group of the Apogon section, the only species, Iris unguicularis, was extremely resistant.

In the laevigata group of the Apogon section, Iris Kaempferi and I. pseudacorus were extremely resistant. Iris virginica showed considerable variation, some plants being very susceptible, others showing various degrees of resistance, and some being very resistant. The Sydows (1904) list $I$. pseudacorus as a host.

In the hexagona group of the Apogon section Iris fulva and one strain of $I$. foliosa (165) were susceptible to the race australis, resistant to the race septentrionalis. Another strain (I55) of Iris foliosa was moderately resistant to race australis.

In the ensata group of the Apogon section the only species, Iris ensata, was extremely resistant. The Sydows list this as a host.

In the longipetala group of the Apogon section only Iris missouriensis was studied. This was susceptible.

In the tripetalous group of the Apogon section only the species Iris setosa was studied. This showed considerable variation, some plants being susceptible and others moderately resistant.

In the verna group of the Apogon section the only species, Iris verna; was extremely resistant.

In the Pardanthopsis section of the genus, Iris dichotoma sometimes gave a susceptible type of reaction and at others showed more or less resistance.

In the Evansia section, Iris cristata was extremely resistant. Iris cristata (lacustris) was moderately resistant. Iris tectorum was usually resistant, although occasionally it produced a moderate number of well-developed uredinia. The Sydows list the latter as a host.

In the Onocyclus section the only species studied, Iris susiana, was very susceptible.

All the iris studied of the Pogoniris section were extremely resistant. Included were Iris Kochii, I. mesopotamica, I. pumila, I. flavescens, I. variegata, and $I$. pallida, as well as many horticultural varieties which, according to Dykes, were probably derived largely from hybrids between $I$. pallida and $I$. variegata. The Sydows list I. flavescens, I. pumila, and I. pallida as hosts. They also list several other species of this group. So far as the writer is aware, rust has apparently only been found once on bearded iris in the United States. W. N. Shear in a letter stated that rust was collected on German iris in 1928 in the vicinity of San Diego, California, but that special pains were 
taken to destroy all infected plants and he was not able to find any rust on this group of iris the next year.

In the Xiphium section the varieties studied of Iris Xiphium and $I$. xiphioides were very susceptible. Iris filifolia was more or less resistant.

The marked susceptibility of Hermodactylus tuberosus is of special interest, since it gives a very susceptible species outside of the genus Iris, although it has been included by some under the name Iris tuberosa.

It is evident that as far as the two races studied of Puccinia Iridis are concerned, there is no correlation between rust reaction and relationship of the species in the genus. Susceptible species were found in such dissimilar sections as Apogon, Onocyclus, Xiphium, and in the genus Hermodactylus, while other species of the sections Apogon and Xiphium showed no signs of infection.

The differences noted between the host range for the rust given by the Sydows and Arthur as contrasted with the susceptible species determined in this study indicate that probably several other races may be distinguished in the species. Part of this discrepancy may possibly be attributed to the strains of the species studied, since, as shown for Iris spuria and I. virginica, different strains of a species may give markedly different reactions. This can hardly explain all of the differences. The marked resistance in these studies of all the Pogoniris section and the Californian group of the Apogon section indicates that there are probably at least two other races differentiated by their specialization to these groups. The marked resistance of such species as Iris foetidissima, $I$. pseudacorus, $I$. ensata, and $I$. sibirica as contrasted with the susceptibility reported by Plowright, the Sydows, and Tranzschel indicates that there may also be races specialized to these species.

Department of Botany,

UNIVERStTY OF MichigAN,

Ann Arbor, Michigan

\section{LITERATURE CITED}

Arthur, J. C. I920. Uredinales. Dicaeoma (?) Iridis (DC.) Kuntze. North American Flora 7: 379-380.

Dykes, W. R. 1913. The genus Iris. Cambridge University Press.

Plowright, C. B. I889. A monograph of the British Uredineae and Ustilagineae. Puccinia Iridis, p. I89-190; Uredo Iridis, p. 257-258.

Sxdow, P. AND H. I904. Monographia Uredinearum. Puccinia Iridis (DC.) Wallr. I: $598-600$.

Tranzschel, W. I923. Experimenta et observationes ad biologiam Uredinalium. I914-19rg. Notulae syst. ex Inst. Cryptog. Horti. Bot. Petropol. 2 (6) : 83-86. 